\title{
Rifampicin-resistance Pattern of Mycobacterium Tuberculosis and Associated Risk Factors Among Presumptive Pulmonary and Extra Pulmonary Tuberculosis Patients at Madda Walabu University Goba Referral Hospital, Southeast Ethiopia
}

Wakuman Taye Kelecha ( $\square$ tayewakuma21@gmail.com )

Madda Walabu University https://orcid.org/0000-0001-5075-9275

Solomon Gebra-Sellasie Teklegiorgis

Addis Ababa University Faculty of Medicine: Addis Ababa University School of Medicine

Mesay Mitiku Gemechu

Madda Walabu University

Research

Keywords: Rifampicin resistant M. tuberculosis, GeneXpert MTB/RIF assay, Risk factors

Posted Date: June 29th, 2021

DOI: https://doi.org/10.21203/rs.3.rs-652594/v1

License: (1) (i) This work is licensed under a Creative Commons Attribution 4.0 International License.

Read Full License 


\section{Abstract}

Background: Drug resistant M.tuberculosis is one of the serious public health trouble that intimidating progress made in tuberculosis cases and control in several countries. Early detection of drug-resistant tuberculosis is crucial for patient management and infection control.

Methods: Hospital based cross-sectional study design was conducted from October 2020 to February 2021. Detection of Mycobacterium tuberculosis and resistance to Rifampicin pattern was determined by using GeneXpert MTB/RIF assay. Data were entered and analyzed by SPSS version 23.0. Bivariate and multivariate analyses were used to examine the relationship between dependent and independent variables. Less than $0.05 \mathrm{P}$-value was used to show significance.

Results: A total of 301 presumptive tuberculosis patients were included in the study; of these, 46 (15.3\%) of them were identified as having Mycobacterium tuberculosis, 2/46 (4.35\%) were resistant to Rifampicin and 4/46 (14.8\%) patients were TB/HIV co-infected. From the total of $M$. tuberculosis detected 40 (16.7\%) were identified in pulmonary and $6(9.8 \%)$ were in extra-pulmonary presumptive patients. Rifampicinresistant $M$. tuberculosis was detected in 2 patients who had a history of taking Anti-tuberculosis drugs.

Conclusion: Previous history of tuberculosis treatment and having close contact history with tuberculosis patients were found as important associated factors that enhance the prevalence of tuberculosis among presumptive tuberculosis patients. This indicates the mandate to make better and oversee the treatment protocol to control the burden of drug resistant M.tuberculosis.

\section{Background}

Tuberculosis (TB) is potentially fatal contagious bacterial disease caused by Mycobacterium tuberculosis (most common cause) that can affect any part of the body, but principally associated with lung diseases (Pulmonary Tuberculosis) and it can also affect other parts of the body, Extra Pulmonary Tuberculosis (EPTB) and remains as an important infectious disease and public health concern worldwide (1).

At the end of 2019, the world as a whole, most WHO regions and many high TB burden countries were not on track to reach the 2020 milestones of the End TB Strategy. Globally, an estimated 10.4 million people fell ill with TB in 2019, (10\% among HIV co-infected individuals), 1.67 million deaths and 490,000 MDRTB plus an additional 110,000 RR-TB cases was reported by WHO. Geographically, most people who developed TB in 2019 were from south-East Asia (44\%), Africa accounts for $(25 \%)$ and the Western Pacific shared (18\%) (2).

Rifampicin resistant tuberculosis is caused by tubercle bacilli that display in vitro resistance to Rifampicin (3) and a good indicator of MDR-TB, because it discloses the existence of more than $90 \%$ Isoniazid and Rifampicin resistance, and regarded as an alternative method for detection of MDR-TB (4). 
Drug-resistant tuberculosis arises due to improper and irrational use of anti-tubercular drugs (ATDs) in treatment of drug-susceptible TB patients, a genetic mutation of bacilli, an inadequate administered treatment regimen and weak services program that lead to delay detection and ineffective treatment of drug resistance and unequipped to support patients to keep adherence to treatment $(5,6)$.

Drug-resistant TB continues to be a public health threat Worldwide including our country Ethiopia. The challenge to the control of DR-TB starts with a delay in diagnosis and the low rate of detection of drug susceptible TB by microscopy. For better patient management and infection control in tuberculosis cases, early detection of drug resistance TB is the most crucial approach $(7,8)$. Therefore, GeneXpert is an automated real-time polymerase chain-reaction assay designed for the rapid and simultaneous detection of MTB and rifampicin resistance. The present study was designed to assess the prevalence and associated risk factors for RIF resistant TB at Madda Walabu University Goba Referral Hospital, Southeast Ethiopia.

\section{Methods}

\section{Study design, area and period}

A Hospital based cross-sectional study design was conducted from October 2020 to February 2021 at Madda Walabu University Goba Referral Hospital (MWU GRH). MWU GRH is located $446 \mathrm{~km}$ Southeast of Addis Ababa. The hospital has more than 120 beds offering different specialized services and serves more than 1.5 million peoples which come from catchment area and different district of the Bale zone.

\section{Study population and sampling techniques}

Presumptive tuberculosis patients who visited MWU GRH and who fulfilled the inclusion criteria were involved in the study. By using the non-probability consecutive sampling technique, 301 presumptive tuberculosis patients who visited the hospital during the study period were involved in the study.

\section{Variables}

Prevalence of $M$. tuberculosis and Rifampicin-resistant $M$. tuberculosis were the dependent variables whereas demographic factors, HIV sero status and treatment related history were the independent variables.

\section{Sample Size}

The sample size was calculated by using a single proportion formula by considering the prevalence of $23.2 \%, 95 \%$ level of confidence $(a=0.5)$, with the tolerable error of $5 \%(d=0.05)$ and Assuming $10 \%$ non-

$$
\mathrm{n}=\underline{\mathrm{Z}^{2} 1-\alpha / 2 \mathrm{P}(1-\mathrm{P})}=274+10 \%=301
$$

response rate.

$$
d^{2}
$$

\section{Specimen collection and processing}


From each study participant presumptive of TB, $4 \mathrm{ml}$ of clinical specimens (either Sputum, Gastric lavage, Lymph node aspirates, or pleural fluid) were collected in a $50 \mathrm{ml}$ falcon tube based on site of presumptive/infection. Clinical specimens were diluted and GeneXpert MTB/RIF assay was carried out as stated by the manufacturer's company. Accordingly, One $\mathrm{ml}$ of clinical sample was treated with $2 \mathrm{~mL}$ of sample reagent containing $\mathrm{NaOH}$ and isopropanol. Then it was shaked gently, homogenized and incubated for 15 minutes at room temperature. Two $\mathrm{mL}$ of the treated samples were transferred into the cartridge and then loaded into the GeneXpert instrument. Delayed samples were stored in the deep freezer $-20^{\circ} \mathrm{C}$ until processed.

\section{GeneXpert MTB/RIF Assay test principle}

A semi quantitative nested real-time PCR designed to amplify the 81-bp hot-spot region of the rpo $\beta$ gene within Rifampin-resistance determining region (RRDR) and probing the region subsequently for RIFresistance related mutations. The assay tests for MTB and mutations associated with Rifampicin resistance directly from clinical samples in less than 2 hours.

\section{GeneXpert MTB/RIF Quality assurance}

Both Sample processing control and Probe check control internal controls were used. Sample processing control ensures the sample was correctly processed and Probe check control verifies that the steps of the tests taken place correctly.

\section{Data Quality Assurance}

Data quality was ensured through the use of structured questionnaires and intensive supervision during data collection. The patient's mouth was rinsed twice with water before sputum was collected in a sterile container. The GeneXpert MTB/RIF cartridges were stored at $2-28{ }^{\circ} \mathrm{C}$, the cartridge was used within 4 hours after opening the cartridge lid, and powder-free glove was used because powdered gloves interfere with molecular detection.

\section{Data analysis and interpretation}

Data were entered and analyzed by using SPSS version 23.0 software. Frequency and percentage was calculated to summarize the results. Bivariate and multivariate logistic regressions were performed to compute the effect of independent variables on the dependent variable. Those results with $p$-value $<0.05$ at $95 \%$ confidence interval were regarded as statistically significant.

\section{Results}

Prevalence of Mycobacterium tuberculosis

The overall prevalence of detected M. tuberculosis among presumptive tuberculosis patients was 46 (15.3\%). M. tuberculosis was notified in 40 (16.7\%) pulmonary suspected patients and in $6(9.8 \%)$ extra- 
pulmonary suspected tuberculosis patients. The rate of TB/HIV co-infection was 4/46 (8.7\%) (Table 1).

Rifampicin resistant M. tuberculosis

Of the 46 GeneXpert detected Mycobacterium tuberculosis cases, the overall prevalence of rifampicin resistant Mycobacterium tuberculosis was 2 (4.35\%). The rifampicin resistant Mycobacterium tuberculosis cases were detected in pulmonary presumptive drug resistant tuberculosis patients and in patients who had a previously history of TB treatment (Table 1).

\section{Risk factors among tuberculosis presumptive}

Multivariate analysis showed that $M$. tuberculosis infection was significantly associated with participants aged between 15 and 39 years ( $A O R=6.67 ; \mathrm{Cl} 0.54-2.0$ ), previous history of TB treatment $(A O R=3.1, \mathrm{Cl} 0$ 1.29), Contact with $T B$ patient $(A O R=3.38, \mathrm{Cl} 0.17-0.85)$ and frequent use of congested transportation $(A O R=1.1, \mathrm{Cl} 0.01-0.52)$ (Table 2). 
Table 1

Prevalence of $M$. tuberculosis and Rifampicin resistant $M$. tuberculosis among presumptive pulmonary and EPTB patients at MWU GRH, October 2020 to February 2021

\begin{tabular}{|c|c|c|c|c|c|c|}
\hline \multirow[t]{3}{*}{ Variables } & & \multicolumn{2}{|c|}{ M. tuberculosis } & \multirow{3}{*}{$\begin{array}{l}\text { Total } \\
\text { No } \%\end{array}$} & \multicolumn{2}{|c|}{ Resistance pattern } \\
\hline & & \multirow{2}{*}{$\begin{array}{l}\text { Detected } \\
\text { No } \%\end{array}$} & \multirow{2}{*}{$\begin{array}{l}\text { Not } \\
\text { detected } \\
\text { No \% }\end{array}$} & & & \\
\hline & & & & & No \% & No $\%$ \\
\hline \multirow[t]{2}{*}{ Sex } & Male & $28(17)$ & $137(83)$ & $\begin{array}{l}165 \\
(54.8)\end{array}$ & $1(3.6)$ & $27(96.4)$ \\
\hline & Female & $\begin{array}{l}18 \\
(13.2)\end{array}$ & $\begin{array}{l}118 \\
(86.8)\end{array}$ & $\begin{array}{l}136 \\
(45.2)\end{array}$ & $1(5.6)$ & $17(94.4)$ \\
\hline \multirow[t]{4}{*}{ Age } & $<15$ & $6(9.5)$ & $57(90.5)$ & $\begin{array}{l}63 \\
(20.9)\end{array}$ & & $6(100)$ \\
\hline & $15-39$ & $\begin{array}{l}31 \\
(22.8)\end{array}$ & $\begin{array}{l}105 \\
(77.2)\end{array}$ & $\begin{array}{l}136 \\
(45,2)\end{array}$ & & $29(93.5)$ \\
\hline & $40-59$ & $8(10.4)$ & $69(89.6)$ & $\begin{array}{l}77 \\
(25.6)\end{array}$ & & $8(100)$ \\
\hline & $>60$ & $1(4)$ & $24(96)$ & $\begin{array}{l}25 \\
(8.3)\end{array}$ & & $1(100)$ \\
\hline \multirow[t]{2}{*}{ Residence } & Urban & $\begin{array}{l}12 \\
(11.4)\end{array}$ & $93(88.6)$ & $\begin{array}{l}105 \\
(34.9)\end{array}$ & & $12(100)$ \\
\hline & Rural & $\begin{array}{l}34 \\
(17.3)\end{array}$ & $\begin{array}{l}162 \\
(82.7)\end{array}$ & $\begin{array}{l}196 \\
(65.1)\end{array}$ & $2(5.9)$ & $32(94.1)$ \\
\hline \multirow[t]{3}{*}{ Family size } & $<4$ & $9(12.5)$ & $63(87.5)$ & $\begin{array}{l}72 \\
(23.9)\end{array}$ & & $9(100)$ \\
\hline & $4-7$ & $\begin{array}{l}22 \\
(13.4)\end{array}$ & $\begin{array}{l}142 \\
(86.6)\end{array}$ & $\begin{array}{l}164 \\
(54.5)\end{array}$ & & $22(100)$ \\
\hline & $>7$ & $\begin{array}{l}15 \\
(23.1)\end{array}$ & 50 (76.9) & $\begin{array}{l}65 \\
(21.6)\end{array}$ & $2(13.3)$ & 13 (86.7) \\
\hline \multirow[t]{3}{*}{ Drinking milk } & Raw & $\begin{array}{l}39 \\
(17.8)\end{array}$ & $\begin{array}{l}180 \\
(82.2)\end{array}$ & $\begin{array}{l}219 \\
(72.8)\end{array}$ & $2(5.1)$ & 37 (94.9) \\
\hline & Boiled & $7(9.5)$ & $67(90.5)$ & $\begin{array}{l}74 \\
(24.6)\end{array}$ & & $7(100)$ \\
\hline & No & $0(0)$ & $8(100)$ & $8(2.7)$ & & 0 \\
\hline \multirow[t]{2}{*}{ Smoking cigarette } & No & $\begin{array}{l}43 \\
(15.1)\end{array}$ & $\begin{array}{l}242 \\
(84.9)\end{array}$ & $\begin{array}{l}285 \\
(94.7)\end{array}$ & $2(4.7)$ & $41(95.3)$ \\
\hline & Yes & $3(18.8)$ & $13(81.2)$ & $\begin{array}{l}16 \\
(5.3)\end{array}$ & & $3(100)$ \\
\hline Drinking alcohol & Yes & $5(9.4)$ & $48(90.6)$ & 53 & & $5(100)$ \\
\hline
\end{tabular}


(17.6)

\begin{tabular}{|c|c|c|c|c|c|c|}
\hline & No & $41(16.5)$ & $\begin{array}{l}207 \\
(83.5)\end{array}$ & $\begin{array}{l}248 \\
(82.4)\end{array}$ & $2(4.9)$ & $39(95.1)$ \\
\hline \multirow[t]{2}{*}{$\begin{array}{l}\text { Congested } \\
\text { transportation }\end{array}$} & Yes & $\begin{array}{l}42 \\
(18.8)\end{array}$ & $\begin{array}{l}182 \\
(81.2)\end{array}$ & $\begin{array}{l}224 \\
(74.4)\end{array}$ & $2(4.8)$ & $40(95.2)$ \\
\hline & No & $4(5.2)$ & $73(94.8)$ & $\begin{array}{l}77 \\
(25.6)\end{array}$ & & $4(100)$ \\
\hline \multirow[t]{2}{*}{ Contact with TB patient } & Yes & $\begin{array}{l}16 \\
(26.7)\end{array}$ & $44(73.3)$ & $\begin{array}{l}60 \\
(19.9)\end{array}$ & $2(12.5)$ & $14(87.5)$ \\
\hline & No & $\begin{array}{l}30 \\
(12.4)\end{array}$ & $\begin{array}{l}211 \\
(87.6)\end{array}$ & $\begin{array}{l}241 \\
(80.1)\end{array}$ & & $30(100)$ \\
\hline \multirow[t]{2}{*}{$\begin{array}{l}\text { Previous history of TB } \\
\text { treatment }\end{array}$} & Yes & $\begin{array}{l}13 \\
(24.1)\end{array}$ & $41(75.9)$ & $\begin{array}{l}54 \\
(17.9)\end{array}$ & $2(15.4)$ & $11(84.6)$ \\
\hline & No & $\begin{array}{l}33 \\
(13.4)\end{array}$ & $\begin{array}{l}214 \\
(86.6)\end{array}$ & $\begin{array}{l}247 \\
(82.1)\end{array}$ & & $33(100)$ \\
\hline \multirow[t]{2}{*}{ HIV infection } & Negative & $\begin{array}{l}42 \\
(15.3)\end{array}$ & $\begin{array}{l}232 \\
(84.7)\end{array}$ & $\begin{array}{l}274 \\
(91)\end{array}$ & $2(4.8)$ & $40(95.2)$ \\
\hline & Positive & $4(14.8)$ & $23(85.2)$ & $27(9)$ & & $4(100)$ \\
\hline \multirow[t]{2}{*}{ Site of infections } & Pulmonary & $\begin{array}{l}40 \\
(16.7)\end{array}$ & $\begin{array}{l}200 \\
(83.3)\end{array}$ & $\begin{array}{l}240 \\
(79.7)\end{array}$ & $2(5)$ & $38(95)$ \\
\hline & EPTB & $6(9.8)$ & $55(90.2)$ & $\begin{array}{l}61 \\
(20.3)\end{array}$ & & $6(100)$ \\
\hline
\end{tabular}


Table 2

Bivariate and Multivariate analysis which shows the relationship between risk factors and prevalence of M. tuberculosis at MWU GRH, October 2020 to February 2021

\begin{tabular}{|c|c|c|c|c|c|}
\hline \multicolumn{2}{|l|}{ Variables } & $\begin{array}{l}\text { COR } \\
(95 \% \mathrm{Cl})\end{array}$ & $P-V$ & \multirow{3}{*}{$\begin{array}{l}\text { AOR } \\
(95 \% \mathrm{Cl})\end{array}$} & \multirow[t]{3}{*}{$P-V$} \\
\hline \multirow[t]{2}{*}{ Sex } & Male & \multirow{2}{*}{$\begin{array}{l}0.746 \\
(0.39-1.41)\end{array}$} & \multirow[t]{2}{*}{0.371} & & \\
\hline & Female (Ref) & & & & \\
\hline \multirow[t]{7}{*}{ Age } & \multicolumn{5}{|l|}{$<15$ (Ref) } \\
\hline & \multirow[t]{2}{*}{$15-39$} & 2.53 & \multirow[t]{2}{*}{0.128} & 6.67 & \multirow[t]{2}{*}{0.038} \\
\hline & & $(0.28-22.12)$ & & $(0.54-82.0)$ & \\
\hline & \multirow{2}{*}{$40-59$} & 7.09 & \multirow[t]{2}{*}{0.060} & 4.04 & \multirow[t]{2}{*}{0.217} \\
\hline & & $(0.92-54.49)$ & & $(0.44-37.12$ & \\
\hline & \multirow[t]{2}{*}{$>60$} & 2.78 & \multirow[t]{2}{*}{0.146} & 1.20 & \multirow[t]{2}{*}{0.874} \\
\hline & & $(0.33-23.41)$ & & $(0.12-11.8)$ & \\
\hline \multirow[t]{5}{*}{ Family size } & \multicolumn{5}{|l|}{$<4$ (Ref) } \\
\hline & \multirow[t]{2}{*}{$4-7$} & 0.476 & \multirow[t]{2}{*}{0.108} & 0.69 & \multirow[t]{2}{*}{0.534} \\
\hline & & $(0.19-1.17)$ & & $(0.22-2.16)$ & \\
\hline & \multirow[t]{2}{*}{$>7$} & 0.51 & \multirow[t]{2}{*}{0.076} & 0.55 & \multirow[t]{2}{*}{0.157} \\
\hline & & $(0.24-1.07)$ & & $(0.24-1.25)$ & \\
\hline \multirow[t]{3}{*}{ Habit of drinking alcohol } & \multirow[t]{2}{*}{ Yes } & 1.90 & \multirow[t]{2}{*}{0.199} & 1.46 & \multirow[t]{2}{*}{0.528} \\
\hline & & $(0.71-5.06)$ & & $(0.44-4.84)$ & \\
\hline & \multicolumn{5}{|l|}{ No (Ref) } \\
\hline \multirow[t]{3}{*}{ Use of congested transportation } & \multirow[t]{2}{*}{ Yes } & 1.23 & 0.008 & 1.09 & 0.007 \\
\hline & & $(0.08-0.68)$ & & $(0.01-0.52)$ & \\
\hline & No (Ref) & & & & \\
\hline Contact with TB patient & Yes & 2.39 & 0.007 & 3.38 & 0.020 \\
\hline & & $(0.19-0.77)$ & & $(0.17-.85)$ & \\
\hline & No (Ref) & & & & \\
\hline
\end{tabular}

AOR: Adjusted Odds ratio, COR: Crude Odds ratio, Cl: Confidence interval, Ref: Reference category, Bold p-value: Significant association 


\begin{tabular}{|c|c|c|c|c|c|}
\hline \multirow[t]{3}{*}{ Previous history of TB treatment } & \multirow[t]{2}{*}{ Yes } & 2.48 & \multirow[t]{2}{*}{0.005} & 3.09 & \multirow[t]{2}{*}{0.007} \\
\hline & & $(0.23-1.0)$ & & \multirow{2}{*}{\multicolumn{2}{|c|}{$(0-1.29)$}} \\
\hline & No (Ref) & & & & \\
\hline \multirow[t]{3}{*}{ HIV infection } & \multicolumn{5}{|l|}{ Negative (R) } \\
\hline & \multirow[t]{2}{*}{ Positive } & 1.04 & \multirow[t]{2}{*}{0.074} & 0.57 & \multirow[t]{2}{*}{0.398} \\
\hline & & $(0.34-3.16)$ & & $(0.16-2.06)$ & \\
\hline \multirow[t]{3}{*}{ Site of infections } & \multirow[t]{2}{*}{ Pulmonary } & 1.83 & \multirow[t]{2}{*}{0.191} & 1.63 & \multirow[t]{2}{*}{0.338} \\
\hline & & $(0.73-4.54)$ & & $(0.59-4.5)$ & \\
\hline & \multicolumn{5}{|l|}{ EPTB (Ref) } \\
\hline $\begin{array}{l}\text { AOR: Adjusted Odds ratio, COR: C } \\
\text { Bold p-value: Significant associat }\end{array}$ & e Odds ratio, & Confidence in & val, Ref: & eference cate & ry, \\
\hline
\end{tabular}

\section{Discussion}

The overall prevalence of Mycobacterium tuberculosis

In the present study, the overall prevalence of $M$. tuberculosis among presumptive TB patients was $15.3 \%$, which is in agreement with studies conducted in Addis Ababa 15.1\% (9), Hiwot Fana 15.7\% (10), Felege Hiwot and Debre Tabor $14.6 \%$ (11). However, result from our study was lower than studies done in India $32.9 \%$ (12), Egyptian 19\% (13), Gambo 22.4\% (14) and Debre Markos 23.2\% (15). The possible reasons attributable for such inconsistency were variation in subset of targeted population, setting and locations where the data was collected, and framework of study design. In contrast, it is higher than studies conducted in other parts of Ethiopia like Ataye 8.98\% (16) and Tigray 7.9\% (17). This lower prevalence and discrepancy in estimation with the current study might be due to dissimilarities in nature of study subjects and geographical area.

Rifampicin resistant Mycobacterium tuberculosis

In this study, the prevalence of rifampicin-resistant $M$. tuberculosis was $4.35 \%$. This result is congruent with studies done in Afar 4.3\% (18), Hiwot Fana 4.1\% (10), and Debre Berhan 5.2\% (19). However, it was higher than studies conducted in India $2.7 \%$ (20), Nigeria 2.4\% (21) and Gambo 0.3\% (14). This might be due to majority of TB suspected were new cases and differences in TB control and prevention program among countries. To the contrary, there was a lower reported prevalence of rifampicin-resistant $M$. tuberculosis from Eastern Uttar Pradesh 26.1\% (12), Debre Markos 10.3\% (15) and Gondar 15.8\% (22). This lower prevalence and inconsistency could be due to difference in history of taking Anti-tuberculosis drugs, possibility of HIV/AIDS acquisition and TB, TB/HIV and MDR-TB prevention and control program.

\section{Associated factors of tuberculosis infections among TB presumptive}


The prevalence of $M$. tuberculosis was $17 \%$ in males and $13.2 \%$ in females but no statistically significant association was observed. This study is in agreement with WHO 2020 report (23), India (12), Nigeria (21), St. Peter Tuberculosis Specialized Hospital (24), and Felege Hiwot and Debre Tabor (11). This Variation could be due to difference in community cultural expectations on attempt to get healthcare services, having habit of smoking and alcoholism, high level exposure of males to surrounding.

The results of our study showed that the assessed TB/HIV co-infection rate was $8.7 \%$, which is comparable with studies done at Ataye 7.89\% (16), Addis Ababa 6.7\% (9) and WHO 2020 report (8.2\%) (23). However, high rate of TB/ HIV co-infection was reported from southwest Ethiopia 35.5\% (25), Felege Hiwot and Debre Tabor 41.9 \% (11), and Gondar 23.8 \% (22). This inconsistency could be due to difference in the high burden of HIV setting area, Lack of awareness of TB/HIV co-morbidity among communities and the extent of performed HIV testing.

The chance of getting M. tuberculosis was 6.67 fold in patients between ages 15-39 when compared to those age $>60$ years, the difference being statistically significant with $p$ value 0.038 . This significance difference may be due to the extent contact of productive ages to the surrounding for different activities and movability from one location to another may be results in chance of getting tuberculosis bacilli. Our result is in agreement with similar studies in Pakistan (26), Nigeria (21) and Debre Berhan (19), and Gambella (25).

The prevalence of $M$. tuberculosis among previously treated patients was higher $24.1 \%$ than treatment new patients $13.4 \%$, with statistical significant difference $(P<0.050)$. Our finding agrees with studies done at Nepal (27), Hiwot Fana (10) and St. Peter Tuberculosis Specialized Hospital (24). High prevalence of rifampicin resistant $M$. tuberculosis was also detected among patients who had a history of previously taking anti-tuberculosis drugs (15.4\%) which is comparable with studies from Eastern Uttar Pradesh (12), Nepal 13.79\% (27) and Addis Ababa 27.4\% (9).This might be due to lack of success from previous tuberculosis treatment history and patients with previously history of taking anti-tuberculosis drugs were more likely to harbor drug-resistant bacilli because of previous exposure of bacilli to TB agents.

In this study, high prevalence of pulmonary tuberculosis $16.7 \%$ was detected when compared with extrapulmonary tuberculosis which was $9.8 \%$. This result agrees with a study done at Pakistan (26), Egyptian (13) and Hiwot Fana (10). This shows that pulmonary tuberculosis infection has inflated chance of transmission from pulmonary tuberculosis patients during coughing, sneezing and others way of bacilli transmission.

The result of this study also showed frequent utilization of congested transportation had a significant association $(p<0.05)$ with the prevalence of drug susceptible tuberculosis and drug resistance tuberculosis. The possible reason for such significance could be there is chance of acquiring bacilli from the index cases because of denied of opening window for different reasons and lack of ventilation during voyage. This study agrees with study done at Ataye (16). 
The prevalence of detected M. tuberculosis in relation to contact history with TB patients among TB presumptive was analyzed and showed significance difference. The prevalence of $M$. tuberculosis was higher $26.7 \%$ in patients who had history of contact with TB patients than who had no history of contact with TB patients $12.4 \%$, the difference being statistically significant with $p$ value 0.02 The reasons for this high prevalence of $M$. tuberculosis in patients who had history of contact with TB patients might be due to the patients have poor adherence and acquiring of bacilli from TB patients. Our finding is supported by similar study from Ataye District Hospital (16) and Dubti Hospital (18).

\section{Limitation of the study}

This study was conducted in a single institution. It would have been better if we incorporated a number of health institutions for a better representation of study subjects. This study also lacks any other diagnostic tool that can be used as gold standard like culture (LJ or MGIT).

\section{Conclusion}

The overall prevalence of $M$. tuberculosis among tuberculosis presumptive patients was $15.3 \%$. Of the total detected $M$. tuberculosis, $4.35 \%$ of them were resistant for rifampicin. The TB/HIV co-infection rate was $8.7 \%$ among presumptive tuberculosis patients. The finding obtained from this study has showed that having history of taking anti-tuberculosis drugs, frequent utilization of transportation and close contacts with tuberculosis patients were significantly associated with the prevalence of M.tuberculosis and rifampicin resistant M.tuberculosis. Early diagnosis of tuberculosis and drug resistant tuberculosis should be seriously implemented for prompt treatment and better outcome. Therefore, it is important to sustain the use of GeneXpert test for rapid diagnosis of tuberculosis and rifampicin resistance at the target hospitals and other similar health facilities.

\section{Abbreviations}

AAU: Addis Ababa University; ATDs: Ant-tuberculosis drugs; EPTB: Extra pulmonary tuberculosis; MDR-TB: Multi-drug resistant Tuberculosis; MTB: Mycobacterium tuberculosis; MWU GRH: Madda Walabu university Goba referral hospital; PCR: Polymerase chain reaction; PTB: Pulmonary Tuberculosis; RR-TB: Rifampicin resistance tuberculosis; TB: Tuberculosis; WHO: World Health Organization

\section{Declarations}

\section{Acknowledgements}

We acknowledge staffs of MWU GRH, Department of Microbiology, Immunology and Parasitology of AAU ethical review committee for the ethical clearance, and AAU for Financial support.

\section{Funding}


The research budget is funded by Addis Ababa University

\section{Availability of data and materials}

Anyone interested in the full data in excel format can have a data by writing to tayewakuma21@gmail.com

\section{Author's contributions}

WT conceived and designed the study, involved in GeneXpert MTB/RIF assay, interpret the result, performed the statistical analysis and wrote the manuscript, SG and MM revised the manuscript. All authors read and approved the final manuscript.

\section{Ethics approval and consent to participate}

The proposal was approved by the ethical review committee of AAU. An Official letter was written from the university to MWU GRH administrator and the hospital granted permission for sample collection. The result of the study was communicated to the responsible bodies for any beneficiary or corrective measures.

\section{Consent for publication}

Not applicable

\section{Competing interest}

All authors declare that they have no competing interest.

\section{References}

1. World Health Organization. Definitions and reporting framework for tuberculosis-2013 Revision. 2013

2. World Health Organization. Global tuberculosis report. Geneva: World Health; 2019

3. Ormerod LP. Multi-drug resistant tuberculosis (MDR-TB) epidemiology, prevention and treatment. British Medical Bulletin. 2005; 73 and 74:17-24

4. Riordan P, Schwab U, Logan S, et al. Rapid molecular detection of rifampicin resistance facilitates early diagnosis and treatment of multi-drug resistant tuberculosis. PLOS ONE. 2008; 3:1-7

5. Gautama PB, Mishra A, Kumar S. Prevalence of rifampicin resistant Mycobacterium tuberculosis and associated factors among presumptive tuberculosis patients in eastern Uttar Pradesh: a cross sectional study. International Journal of Community Medicine and Public Health. 2018 May 22; 5(6):2271-6

6. Guidelines on programmatic management of drug resistant tuberculosis in India, Revised National Tuberculosis Control Program. 2017 
7. Boehme CC, Nabeta P, Hillemann D. Rapiad molecular detection of tuberculosis and rifampin resistance". New England Journal of Medicine.2010; 363(11):1005-15

8. Walusimbi S, Bwanga F, De Costa A, Haile M, Joloba M, Hoffner S. Meta-analysis to compare the accuracy of Gene Xpert, MODS and the WHO 2007 algorithm for diagnosis of smear negative pulmonary tuberculosis. BMC infectious diseases. 2013; 13:507

9. Arega B, Menbere F, Getachew Y. Prevalence of rifampicin resistant Mycobacterium tuberculosis among presumptive tuberculosis patients in selected governmental hospitals in Addis Ababa, Ethiopia. BMC infectious diseases. 2019 Dec 1;19(1):307

10. Bodena D, Ataro Z, Tesfa T. Trend Analysis And Seasonality Of Tuberculosis Among Patients At The Hiwot Fana Specialized University Hospital, Eastern Ethiopia: A Retrospective Study. Risk Management and Healthcare Policy. 2019;12:297

11. Derbie A, Seble W, Daniel M, et al. Xpert MTB/RIF assay for the diagnosis of Mycobacterium tuberculosis and its Rifampicin resistance at Felege Hiwot and Debre Tabor Hospitals, Northwest Ethiopia: a preliminary implementation research. Ethiopian Journal of Health Development. 2016; $30(2): 61-63$

12. Gautama PB, Mishra A, Kumar S. Prevalence of rifampicin resistant Mycobacterium tuberculosis and associated factors among presumptive tuberculosis patients in eastern Uttar Pradesh: a cross sectional study. International Journal of Community Medicine and Public Health. 2018 May 22; $5(6): 2271-6$

13. Ali SA, Hassan RM, Shehata MM. GeneXpert MTB/RIF as a Rapid Diagnostic tool for Diagnosis of Pulmonary, Extra-pulmonary Tuberculosis and Rifampicin Resistance in the Egyptian Population. Journal of Advances in Microbiology. 2018 Dec 8:1-4

14. Ramos JM, Fernández-Muñoz M, Tisiano G, Fano H, Yohannes T, Gosa A, Tesfamariam A, VerduExpositvo C, Romanyk J, Reyes F, Gorgolas M. Use of Xpert MTB/RIF assay in rural health facilities in southern Ethiopia. Archives of Clinical Microbiology. 2017; 8:2.

15. Mulu W, Abera B, Yimer M, Hailu T, Ayele H, Abate D. Rifampicin-resistance pattern of Mycobacterium tuberculosis and associated factors among presumptive tuberculosis patients referred to Debre Markos Referral Hospital, Ethiopia: a cross-sectional study. BMC research notes. 2017 Dec;10(1):8

16. Gebretsadik D, Ahmed N, Kebede E, Mohammed M, Belete MA. Prevalence of tuberculosis by automated GeneXpert rifampicin assay and associated risk factors among presumptive pulmonary tuberculosis patients at Ataye District Hospital, North East Ethiopia. Infection and drug resistance. 2020; 13:1507.

17. Wasihun AG, Dejene TA, Hailu GG. Frequency of MTB and rifampicin resistance MTB using XpertMTB/RIF assay among adult presumptive tuberculosis patients in Tigray, Northern Ethiopia: A cross sectional study. Public Library of Science one. 2020 Nov 4;15(11)

18. Gebrehiwet GB, Kahsay AG, Welekidan LN, Hagos AK, Abay GK, Hagos DG. Rifampicin resistant tuberculosis in presumptive pulmonary tuberculosis cases in Dubti Hospital, Afar, Ethiopia. The Journal of Infection in Developing Countries. 2019 Jan 31; 13(01):21-7 
19. Asfaw T, Terefe A, Nigus M. Patterns and Trends of Rifampicin-Resistance Mycobacterium tuberculosis and Associated Factors among Presumptive Tuberculosis Patients at Debre Berhan Referral Hospital. Journal of Bioprocess and Biotechnology. 2018; 8(339):2.

20. Nair SA, Raizada N, Sachdeva KS, Denkinger C, Schumacher S, Dewan P, Kulsange S, Boehme C, Paramsivan CN, Arinaminpathy N. Factors associated with tuberculosis and rifampicin-resistant tuberculosis amongst symptomatic patients in India: Public Library of Science One. 2016 Feb 26; 11(2).

21. Etim NG, Briyai FO. Prevalence of Pulmonary and Rifampicin-resistant tuberculosis among patients attending Federal Medical Centre, Yenagoa, Bayelsa state, Nigeria. International Journal of Healthcare and Medical Sciences. 2017; 3(11):85-92.

22. Jaleta KN, Gizachew M, Gelaw B, Tesfa H, Getaneh A, Biadgo B. Rifampicin-resistant Mycobacterium tuberculosis among tuberculosis-presumptive cases at University of Gondar Hospital, Northwest Ethiopia. Infection and Drug Resistance. 2017;10:185

23. World Health Organization. Global tuberculosis report 2019. Geneva: World Health Organization Press; 2020.

24. Araya S, Negesso AE, Tamir Z. Rifampicin-Resistant Mycobacterium tuberculosis Among Patients with Presumptive Tuberculosis in Addis Ababa, Ethiopia. Infection and Drug Resistance. 2020;13:3451

25. Ejeta E, Beyene G, Bonsa Z, Abebe G. Xpert MTB/RIF assay for the diagnosis of Mycobacterium tuberculosis and Rifampicin resistance in high human immunodeficiency virus setting in Gambella regional state, southwest Ethiopia. Journal of clinical tuberculosis and other Mycobacterial diseases. 2018 Aug 1;12:14-20

26. Siddique G, Shafee M, Abbas F, Naeem M, Raziq A, Ahmad S, Babar Km. Mycobacterium tuberculosis; Frequency of rifampin resistance mutations in 81-bp rrdr of rpob gene in Mycobacterium tuberculosis isolates in quetta, pakistan. ProfessionalMedical Journal. 2019 June $1 ; 26(5)$.

27. Ikuabe PO, Ebuenyi ID. Prevalence of rifampicin resistance by automated Genexpert rifampicin assay in patients with pulmonary tuberculosis in Yenagoa, Nigeria. The Pan African Medical Journal. 2018; 29. 